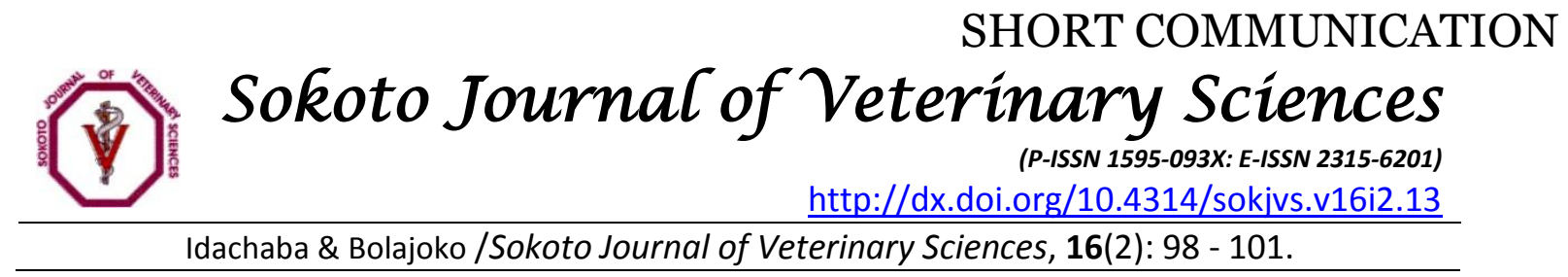

\title{
The need for one health approach towards rabies control in Plateau State, Nigeria
}

\author{
SE Idachaba \& MB Bolajoko*
}

Epidemiology Section, Central Diagnostic Laboratory, National Veterinary Research Institute, Vom, Plateau State, Nigeria

*Correspondence: Tel.: +2349098624092; E-mail: mbbolajoko@gmail.com

\begin{abstract}
Copyright: (C) 2018 Idachaba \& Bolajoko. This is an open-access article published under the terms of the Creative Commons Attribution License which permits unrestricted use, distribution, and reproduction in any medium, provided the original author and source are credited.

Publication History:

Received: 14-09- 2017

Accepted: 27-12-2017

Abstract

Rabies, being a fatal, viral, zoonotic and vaccine-preventable disease, requires a holistic and team approach by all trained professionals working in the various aspects of public health maintenance. The one Health concept is founded on the awareness of the many benefits of controlling pathogens at the human-animal-environmental interface. Questionnaires were administered to the public and health personnel across the seventeen local government areas of Plateau Stateto collect information on factors that bothers on the public's perception of rabies occurrence and control. These factors have been reported in previous and more recent studies to contribute to rabies in the state. They include the level of awareness of rabies and its control by the public, dog ownership and management practices, routine vaccination of dogs against rabies, reporting dog bites and suspected rabies cases to designated health authorities and role of the health personnel in rabies control. The information and data collected were analyzed using Microsoft Excel 2016. The study period spanned from $1998-2007$. The findings of this study led to the conclusion that the creation of a one Health Initiative will stimulate a successful and sustainable control of rabies in the state.
\end{abstract}

Keywords: Nigeria, One health, Plateau state, Rabies, Vaccine-preventable

\section{Introduction}

One health $(\mathrm{OH})$ as a concept is not a new initiative (Kahn et al. 2007a; Kahn et al., 2007b). Presently, it has become a worldwide strategy; a paradigm shift for the expansion of interdisciplinary collaborations, networking and communications in all aspects of health care for humans and animals (Kahn et al., 2007a; Kahn et al., 2007b; Dahal \& Kahn, 2014). Essentially, $\mathrm{OH}$ seeks to promote interdisciplinary collaborations between different disciplines such as the veterinarians, physicians, environmental and public health experts, osteopaths, virologists, wildlife professionals, biochemists, behavioral scientists, dentists, nurses, biomedical engineers, plant biologists and epidemiologists among others to attain optimal health for all; humans, animals and the environment (Kahn, 2011; Aenishaenslin et al., 2013). The $\mathrm{OH}$ concept enhances and employs the knowledge of the interactions between animals, humans, and the environment and how these interactions affect the occurrence, spread, maintenance and other dynamics of infectious diseases (Zinsstag et al., 2005; Dahal \& Kahn, 2014).

Hippocrates, the famous ancient Greek physician is known to be one of the oldest advocator of the concept of $\mathrm{OH}$ through a clean environment, when he wrote on "Airs, Waters and Places" (Hippocrates, $400 C E)$. Another early proponent of $\mathrm{OH}$ is Rudolf Virchow (1821-1902) (Kahn et al., 2007b). Through his contributions and support for the incorporation of veterinary medicine in human health care, he 
successfully launched the $\mathrm{OH}$ concept in the 19th century (Kahn et al., 2007a; Kahn et al., 2007b). His claim that "between animal and human medicine there are no dividing lines, nor should there be" still holds true to the present day (Zinsstag et al., 2005; Kahn et al., 2007b). Thus, the knowledge that human and animal health is linked within the environment shared by humans and animals cannot be overemphasized (Hippocrates, 400CE; Dahal \& Kahn, 2014).

Increasingly, more pathogens that cause diseases in humans are equally zoonotic diseases of animals that can infect people (Zinsstag et al., 2005; Dahal \& Kahn, 2014). And most of the emerging infectious diseases are zoonotic as well. Known and unknown zoonotic diseases are emerging into human populations as the natural world and/or the wild is being increasingly interfered with (Zinsstag et al., 2005; Dahal \& Kahn, 2014). It is now very evident that, the challenges of the 21st century require a new paradigm in health and disease, that is, the one health initiative. We know, pathogens cross species and political borders, hence, the growing worldwide movement of one health, but the concept needs widespread support and acceptance (Kahn, 2011; Kahn et al., 2007b).

Rabies, being a fatal, viral, zoonotic and vaccinepreventable disease, requires a holistic and team approach by all trained professionals working in the distinct aspects of public health maintenance (Bernard, 2014; WHO, 2015). Owing to the holistic nature of $\mathrm{OH}$ activities, a wide range of benefits can be accessed and harnessed towards sustainable rabies control ranging from socioeconomic to environmental health. It is expected that workers in the different fields of public health maintenance and organizations will work together as a $\mathrm{OH}$ team achieving a common good for the public (Bernard, 2014; Hasler et al., 2014).

One health concept encourages a synergy amongst scientists from the public health and environmental science fields to control and mitigate the adverse effect of the occurrence of diseases in the society. Therefore, this study aims to make evident the need to adopt and apply $\mathrm{OH}$ to the control and prevention of the occurrence of rabies in the human-animalenvironmental interface in Plateau Stateof Nigeria.

\section{Materials and Methods}

\section{Study area}

The study area; Plateau Stateof Nigeria is almost centrally located between latitude $80^{\circ} 24^{\prime} \mathrm{N}$ and longitude $80^{\circ} 32^{\prime}$ and $100^{\circ} 38^{\prime}$ east (Anon, 2018). The Statehas a high altitude, approximately 1,200 to a peak of 1,829 metres above the sea level and has a near temperate climate with an average temperature from 18 to $22^{\circ} \mathrm{C}$ (Anon, 2018). The mean annual rainfall can vary from $131.75 \mathrm{~cm}$ to 146 $\mathrm{cm}$ (Anon, 2018). Administratively, the Stateis divided into 17 local government areas (LGA). The LGA include Barkin Ladi, Jos South, Jos North, Jos East, Wase, Bassa, Pankshin, Shendam, Kanam, Kanke, Quampam, Riyom, Mangu, Bokkos, Langtang North, Langtang South and Mikang (Anon, 2018).

\section{Survey}

Structured questionnaires were distributed across all the seventeen LGA of the Stateto assess the general public's perception of the incidence, control and prevention of rabies. The factors considered for this assessment included: the level of awareness of rabies and its control by the public; dog ownership and management practices; routine vaccination of dogs against rabies; reporting dog bites and suspected rabies cases to designated health authorities and role of the health personnel in rabies control. These factors have been reported to still be among major variables contributing largely to the prevalence of rabies in the State(Tekki et al., 2013; Bolajoko, 2014: Tekki et al., 2016). Information from respondents were collated and analyzed as described by Thrusfield (2005).

The data and information collected were analyzed using Microsoft Excel 2016 ${ }^{\circledR}$ to determine the descriptive indices of rabies epidemiology in the Statewithin the study period. Effectively, the level of awareness of rabies and the risks of exposure of both animals and humans to rabies in the communities were measured.

A total of eight hundred and fifty questionnaires were administered; with fifty copies distributed to members of the public in each of the LGA. The questionnaires were administered to respondents that were in attendance during organized anti-rabies campaigns in the state. Where necessary, purposeful informal interviews with respondents and medical health workers in attendance were carried out.

\section{Results and Discussion}

Out of the eight hundred and fifty questionnaires that were administered, we received completed questionnaires from five hundred and eleven respondents. We found that one hundred and eighty-nine $(37 \%)$ of the respondents had a good knowledge of rabies disease and its danger. Fiftynine $(11.6 \%)$ of respondents had fair knowledge about its prevention, while only sixty-six (12.9\%) had a fair idea of the first aid measures to be taken on 
event of a sustained dog bite. However, further analysis of the generated data revealed that Four hundred and fifty-five (89.1\%) of all respondents will follow-up hospital treatment of dog-bite victim until recovery. Furthermore, only Twenty-seven (5.3\%) respondents were aware of prophylactic measures recommended for dog handlers/owners, while two hundred and sixty-nine (52.6\%) were aware of the annual dog vaccination regimen.

Five $(50 \%)$ of the medical personnel all agree that the general public's education about rabies is not enough to contribute to the reduction in the prevalence level of rabies across the Stateand that many of the rural populace still believe in the myths surrounding rabies disease from their local beliefs. Additionally, three (30\%) of the medics believe that the environmental department of the Statewill help a great deal if they stepped up the cleaning of the environment and the disposal of waste. All the medical personnel also agreed that aggressive and sustained public health education on rabies disease will help the communities a great deal, thereby ensuring the sustainability of the control measures to be instituted.

The findings of this study suggest that One Health $(\mathrm{OH})$ as a holistic concept can be instituted to stimulate sustainable rabies control in Plateau state. The $\mathrm{OH}$ initiative is one that adds value through the closer cooperation amongst professionals (Okello et al., 2014). As such, it should provide a platform of added value for sustainable rabies control, in terms of human and animal health, socio-economic and environmental benefits for the public in the humananimal-environmental interface in space and time.

Explosion in human population, expansive and increased agricultural practices, deforestation, livestock grazing, and trade routes and travel have all contributed to increased interactions between animals, humans and wildlife species within the shared environment, leading to sustained maintenance and re-emergence of known diseases and emergence of unknown diseases (Zinsstag et al., 2005; Dahal \& Kahn, 2014). For example, widespread deforestation and intensive agricultural practices led to the emergence of the Nipah virus in Malaysia in late 1990s (Pulliam et al., 2012) and massive $Q$ fever outbreak in the Netherlands in 2007 to 2009 respectively (Aenishaenslin et al., 2013; Dahal \& Kahn, 2014). Furthermore, the emergence of avian influenza and the severe acute respiratory syndrome are excellent proofs of the need for greater partnerships and collaborations between multiple disciplines or sectors for optimal maintenance of animal and human health (Dahal \& Kahn, 2014).
Thus, implementations of effective surveillance, monitoring and control measure across species are possible only by bridging the organizational gaps between animal, human and environmental health sectors (Kahn et al., 2007a; Kahn et al., 2007b; Pulliam et al., 2012). The US Department of Agriculture, US Centers for Disease Control and Prevention (CDC), World Bank, World Health Organization (WHO), Food and Agriculture Organization of the United Nations (FAO), World Organization for Animal Health (OIE), United Nations System Influenza Coordination (UNSIC), European Commission and other entities all recognize the potential of the $\mathrm{OH}$ as a major strategy of disease control and prevention. (Pulliam et al., 2012; Cardiff et al., 2008).

Okello et al. (2014) posits that the $\mathrm{OH}$ concept shows very good possibilities of team cooperation. They further explained that the $\mathrm{OH}$ team should consist of the social workers, physician, veterinarian, public health practitioner, extension workers, environmentalist or ecologist and laboratory scientists and many more; who will work together to synergize the effort and contributions of one another. This will be very applicable in Plateau State(and Nigeria as a whole) because the prevailing socio-economic status of the susceptible human population is closely knitted to their interactions with animals within their shared environment (Bolajoko, 2014).

One Health as a concept, recognizes that the health of humans, animals and the ecosystems is connected, as such, it encourages a coordinated, collaborative, interdisciplinary and cross-sectional approaches. $\mathrm{OH}$ has been with us for many years, yet it is only recently being discussed as a way of mitigating risks in society (Hasler et al., 2014). In this present report, we are advocating the creation of $\mathrm{OH}$ team and initiative, which if created, should contribute towards a sustainable mitigation and control of rabies in all communities of the state. The control of rabies in Plateau Stateshould be encouraged vigorously by focusing on the resident populations in all seventeen LGA. Thus, a total package of education on rabies prophylactic measures, first aid, disposal of waste, care of dogs to discourage proliferation of stray dogs should be established and sustained in the state.

Finally, taking queue from Bernard (2014); we conclude that the success of rabies control via dog vaccination campaign will be better sustained in the state, if one health approach is adopted efficiently and effectively. This idea is also supported by Lembo et al. (2010); who explained that the most cost- 
effective means of protecting humans from disease is to combat zoonotic pathogens by controlling them at the source. Since, rabies is zoonotic; this will require adequate infrastructures which include a well-organized surveillance network and diagnostic capabilities of both canine- and human- rabies cases, which is crucial for sustainable monitoring and evaluation of any vaccination campaign. This report could encourage all states of the federation to carry out further studies to control rabies.

\section{References}

Anonymous (2018). Plateau State. http://www.plateaustate.gov.ng/page/at-aglance, retrieved 13-11-2017.

Aenishaenslin C, Hongoh V, Cissé HD, Hoen AG \& Samoura K (2013). Multi-criteria decision analysis as an innovative approach to managing zoonoses: results from a study on Lyme disease in Canada. BMC Public Health, 13: 897.

Bernard V (2014). One Health. Revue Scientifique Et Technique (International Office of Epizootics), 33(2): 369-370.

Bolajoko MB (2014). Risk assessment and demographic distribution of canine rabies in Plateau State, Nigeria, 2004 - 2009. MSc thesis, College of Medicine and Veterinary Medicine, University of Edinburgh. MSc Thesis, University of Edinburgh. Pp 1-54.

Dahal R \& Kahn L (2014). Zoonotic diseases and one health approach. Epidemiology, 10: 21611165.

Cardiff RD, Ward JM \& Barthold SW (2008). One medicine- one pathology: are veterinary and human pathology prepared? Laboratory Investigation, doi:10.1038/labinvest.3700695.

Hasler B, Cornelsen L, Bennani H \& Rushton J (2014). A review of the metrics of One Health benefits. Revue Scientifique Et TechniqueOffice International Des Epizooties, 33(2) 453-464.

Hippocrates (ca. 400BCE). On Airs, Waters, and Places. Translated by Frans Adams in Hygeia, Hygeia: Revista Brasileira de Geografia Médica e da Saúde, 2(3): 1-12.
Kahn LH (2011). The need for one health degree programs. Infection Ecology and Epidemiology, doi 10.3402/iee.v1i0.7919.

Kahn LH, Kaplan B \& Monath TP (2007a). One health in action! Veterinaria Italiana, 45(1): 195208.

Kahn LH, Kaplan B \& Steele JH (2007b). Confronting zoonoses through closer collaboration between medicine and veterinary medicine (as 'one medicine'). Veterinaria Italiana, 43(1): 5-19.

Lembo T, Hampson K, Kaare MT, Ernest E \& Knobel D (2010). The feasibility of canine rabies elimination in Africa: Dispelling doubts with data. PLOS Neglected Tropical Diseases, doi:10.1371/journal.pntd.0000626.

Okello A, Bardash K, Smith J \& Wellburn S (2014). Past Successes and future Challenges in Three African Countries. PLOS Neglected Tropical Diseases, doi:10. 1371/journal.prntd.0002884.

Pulliam JR, Epstein JH, Dushoff J, Rahman SA \& Bunning M (2012). Agricultural intensification, priming for persistence and the emergence of Nipah virus: A lethal batborne zoonosis. Journal of the Royal Society Interface, 9: 89-101.

Tekki I, Ekong P, Olaleye S, Kumbish P \& Okewole P A (2013). A decade of rabies diagnosis: NVRI perspective. National Veterinary Research Institute Seminar Series. Pp 43 - 55.

Tekki SI, Odita $\mathrm{Cl}$, Idachaba ES, Akanbi BO, Moses DG, Barde JI, James AS, Rimfa AG, Kumbish RP, Agama C, Zhakom PN \& Okewole PA (2016). Dog Bites and Rabies: A Decade Perspective in Nigeria (2005-2014). World Veterinary, 6(1): 19-24.

Thrusfield M (2005). Veterinary Epidemiology, third edition. Blackwell Sciences Ltd. Oxford, UK. Pp 26-63.

WHO 2015. Rabies - About rabies, https://www.who.int/rabies/about/en/, retrieved 18-02-2015.

Zinsstag J, Schelling E, Wyss $K$ \& Mahamat MB (2005). Potential of cooperation between human and animal health to strengthen health systems. Lancet, 366: 2142-2145. 